\title{
A study on the normal values of inner canthal, outer canthal, interpupillary distance and head circumference of 3-21 years ijaws
}

\author{
*Osunwoke E.A, Didia B.C, Olotu E.J, Yerikema A.H, \\ Department of Anatomy, Faculty of Basic Medical Sciences, College of Health Sciences, \\ University of Port Harcourt.
}

\begin{abstract}
This research on the normal values of inner intercanthal, outer intercanthal, head circumference and interpupillary distance was carried out on 3-21 years old ljaws. A total number of one thousand subjects comprising five hundred males (500) and five hundred females (500) were randomly selected from Baptist Nursery and primary schools in Biogbolo, Bayelsa state College of Arts and Science Secondary School Agudama Yenagoa, University of Port Harcourt, St Peter's area and Biogbolo town in Yenagoa, Bayelsa State, Nigeria. Measurements were carried out using a vernier caliper, non stretchable plastic ruler and tape respectively. Results showed that the overall mean for inner intercanthal distance, outer intercanthal distance, head circumference, near and far interpupillary distances were $28.30 \pm 4.16 \mathrm{~mm}, 92.49 \pm 6.30 \mathrm{~mm}, 54.46 \pm 2.19 \mathrm{~cm}$, $57.64 \pm 4.49 \mathrm{~mm}$ and $60.47 \pm 4.48 \mathrm{~mm}$ for males while for the females, the values were $28.15 \pm 2.75 \mathrm{~mm}, 91.96 \pm 5.81 \mathrm{~mm}, 54.27 \pm 2.00 \mathrm{~cm}, 56.86 \pm 4.92 \mathrm{~mm}$ and $59.77 \pm 4.95 \mathrm{~mm}$ respectively. The values obtained for males in the near and far interpupillary distance were significantly $(p<0.001)$ higher than that gotten for females. This study is of relevance in clinical practice and forensic investigations.
\end{abstract}

Keywords: Normal values, inner, outer canthal and interpupillary distance, Head circumference, ljaws.

\section{INTRODUCTION}

Anthropometry is a branch of anthropology concerned with measurements of the human body (Donald et al., 1999). It deals with physical differences particularly skeletal and racial groups. The effectiveness in the treatment of a disorder frequently depends on its early detection. Frontooccipital circumference, inner canthal distance, outer canthal distance and interpupillary distance are important measurements in the evaluation of several systemic syndromes, craniofacial abnormalities and in the surgical treatment of post traumatic telecanthus (Laestedius et al., 1979; Farkas et al., 1992a, 1992b). Canthal index and circumference interobital index, which are derived from the measured parameters, are also important to anatomists and craniofacial surgeons (Evereklioglu et al., 2001, Lakshminarayana et al., 1991). A study on the normative values of craniofacial measurements in idiopathic benign macrocephalic children was carried out Evereklioglu et al., (2001). Normal standard values at each age for head circumference, inner canthal distance, outer, canthal index, near and far interpupillary distance was determined for age, sex and race in 7 to 16 years old idiopathic benign macrocephalic children. Mean values for head circumference, inner canthal distance, outer canthal distance, near and distant interpupillary distant and canthal index were: $57.43 \pm 1.46 \mathrm{~cm}, 31.90 \pm 2.41 \mathrm{~mm}$, $89.29 \pm 4.34 \mathrm{~mm}, 58.79 \pm 2.97 \mathrm{~mm}, 62.10 \pm 3.23 \mathrm{~mm}$ and $35.73 \pm 2.24$ respectively in male children. In female children, the values were $56.57 \pm 1.24 \mathrm{~cm}$, $31.45 \pm 2.65 \mathrm{~mm}, \quad 87.71 \pm 4.11 \mathrm{~mm}, \quad 58.16 \pm 3.46 \mathrm{~mm}$, $61.26 \pm 3.66 \mathrm{~mm}$ and $35.84 \pm 2.31$ respectively. Pinzer et al.,(2008) attempted to recognize the multiplicity of definitions in orbital measurements, as well as clarify the confusing terminology used in telecanthus and hypertelorism. They measured the inner canthal, outer canthal and interpupillary distance in 688 KherCambodians. The measured normal values were presented and compared with other Asian populations. It was discovered that the orbital morphometry of Khmer- Cambodians did not resemble the general conception of an Asian appearance but rather showed a similarity to values found in Indians. Kaimbo and Kayembe, (1994) took a measurement of the outer orbital distance, inner canthal distance and interpupillary distance and proptosis on 95 healthy Zairian subjects. The subjects were aged from $2^{1} / 2$ to 18 years comprising 47 boys and 48 girls. The measurements were performed with the Hertel exophthalmometer for the proptosis and the outer orbital distance, with pupillometer model PD-2 for the interpupillary 
distance and with a ruler for inner canthal distance. The mean $\pm S D$ for inner canthal distance was $27.4 \pm 2.7 \mathrm{~mm}$ for the first age group $\left(2^{1} / 2\right.$ to 6 years $)$, $29.7 \pm 3.1 \mathrm{~mm}$ for the second age group (7 to 10 years), $30 \pm 2.4 \mathrm{~mm}$ for the third age group (11 to 14 years) and $32.2 \pm 3.1 \mathrm{~mm}$ for the last age group (15 to 18 years).

In another study conducted by Oladipo et al., (2009) on the canthal indices of Urhobo and Itsekiri ethnic groups of Nigeria, one thousand (1000) adults comprising 500 males and 500 females were used for this study. Five (500) hundred subjects comprising 250 males and 250 females were from the Urhobo ethnic group and 250 males and 250 females from the Itsekiri ethnic group. The results showed that Urhobo males and females had inner intercanthal distances of $3.40 \mathrm{~cm}$ and $3.00 \mathrm{~cm}$ respectively, outer intercanthal distances of $13.10 \mathrm{~cm}$ and $12.10 \mathrm{~cm}$ and mean canthal indices of 24.38 and 29.38 respectively while the Itsekiri males and females had inner intercanthal distances of $3.50 \mathrm{~cm}$ and $3.30 \mathrm{~cm}$ respectively, outer intercanthal distances of $12.90 \mathrm{~cm}$ and $11.40 \mathrm{~cm}$ and mean canthal indices of 26.03 and 27.07 respectively. Canthal index of Urhobo females was larger than that of Itsekiri females and canthal index in Itsekiri males was larger than Urhobo males $(\mathrm{P}<0.05)$.

This study is aimed at demonstrating the anthropometric variations in canthal measurements, head circumference, interpupillary distance and canthal index of 3-21years old ljaws.

\section{MATERIALS AND METHODS}

A total number of one thousand (1000) subjects from ljaw (500 males and 500 females) were selected for this study. The subjects were within the age range of 3- 21 years with normal craniofacial configuration and no known history of neurologic disease, developmental disability, oculofacial trauma, craniofacial congenital anomaly, strabismus and clinically manifest telecanthus and also if their parents up to the second or third generation are of the same tribe. This was determined by physical observation and by personal interview. Those found to have one form of disability or the other were excluded from this study. The age of each subject was determined according to the nearest birthday. Subjects were recruited by cluster sampling from Baptist Nursery and primary schools in Biogbolo, Bayelsa State College of Arts and Science Secondary School Agudama Yenagoa, University of Port Harcourt, St Peter's area and Biogbolo town in Yenagoa, Bayelsa State, Nigeria.
After informed consent has been obtained from the subjects, measurements of inner and outer intercanthal distance, head circumference and interpupillary distance was performed. The mean values for each parameter was noted at each age from 3-21 years and analyzed to statistically assess the anthropometric variation patterns of each parameter with advancing age. Measurements were carried out using a millimeter ruler, a vernier caliper and calibrated tape. This is because this study is primarily designed to observe the anthropometric variation pattern of measured parameters with advancing age. Each subject was seated comfortably in a chair with the subjects head at the same level as and $40 \mathrm{~cm}$ in front of the examiner's head. The subject's face was well illuminated. A digital vernier caliper was used for the measurement of the intercanthal distances. Each measurement was carried out twice to ensure accuracy. The inner intercanthal distance was measured by having the subject look straight at the examiner while the digital vernier caliper was placed in between the bridge of the subject's nose. The subject was instructed to look upward for the outer intercanthal distance to be measured. This is to maximize the contrast between the sclera and the skin. The canthal index (inner intercanthal / outer intercanthal distance in centimeters $\times 100$ ) was calculated from the data. (Evereklioglu et al., 2001). For near interpupillary distance, the examiner's right eye is closed, while the subject had to binocularly fixate a finger held up to the open left eye of the examiner. The zero mark on the ruler was placed at the outer (temporal) limbus margin of the subject's right eye while the examiner sighted with his open left eye the point of the ruler that corresponded to the inner limbus of the subject's left eye. Then the examiner had to close his left eye and ask the subject to look at the examiner's opened right eye moving the fixation finger to the open right eye. This made both eyes to move to the right and as a result, "O" is no longer aligned with the outer (temporal) limbus of the subject's right eye. Measurement of the new position of the nasal limbus of the subject's left eye was taken. This was the measurement of the far/ distant interpupillary distance. Head circumference was obtained by placing the tape just on the external occipital prominence and the supraorbital ridges. Subjects with fashionable hair styles had their hair compressed as much as possible and the tape tightly drawn. In girls with braids, the tape was placed against the skin and not over the lump of hair. 
Statistical analysis was done using SPSS for windows and multiple comparisons were made between the measured parameters, groups and sex by using students T-test

\section{RESULTS}

The result of this study is presented in the tables below. The subjects were divided into four age groups: 3-7, 8-12, 13-17 and 18-21 years. Table 1. Table showing the mean $\pm S D$ for outer intercanthal distance (OCD), inner intercanthal distance (ICD), near interpupillary distance (NIPD), far interpupillary (FIPD), canthal index $(\mathrm{Cl})$ and head circumference (HC) of ljaw males and females. Table2. Table showing mean $\pm S D$ of the normal values for the measured parameters specific for age in males. Table 3. Table showing the mean $\pm S D$ of the normal values for the measured parameters specific for age in females.

Table 1. Table showing the mean \pm SD of the measured parameters in males and females.

\begin{tabular}{|c|c|c|c|c|c|c|c|c|}
\hline \multirow{2}{*}{$\begin{array}{l}\text { Age } \\
\text { group } \\
\text { MALES }\end{array}$} & $\mathrm{N}$ & \multirow{2}{*}{$\begin{array}{c}\mathrm{HC}(\mathrm{cm}) \\
\text { Mean } \pm S D\end{array}$} & $\begin{aligned} \mathrm{C} D & (\mathrm{~mm})\end{aligned}$ & \multicolumn{2}{|c|}{$\mathrm{OCD}(\mathrm{mm})$} & \multirow{2}{*}{ Mean \pm SD } & \multirow{2}{*}{$\begin{array}{l}\operatorname{NIPD}(\mathrm{mm}) \\
\text { Mean } \pm \text { SD }\end{array}$} & \multirow[t]{2}{*}{$\mathbb{P D}(\mathrm{mm})$} \\
\hline & & & Mean $\pm S D$ & Mean $\pm S D$ & Mean $\pm S D$ & & & \\
\hline$\overline{3-7}$ & 155 & $51.48 \pm 1.95$ & $25.11 \pm 1.92$ & 83. & $3 \pm 4.75$ & $30.02 \pm 1.93$ & $51.65 \pm 3.19$ & $54.50 \pm 3.38$ \\
\hline $8-12$ & 87 & $54.33 \pm 1.79$ & $27.16 \pm 1.91$ & & $0 \pm 4.40$ & $29.46 \pm 2.19$ & $57.13 \pm 3.23$ & $59.89 \pm 3.40$ \\
\hline $13-17$ & 170 & $55.43 \pm 1.51$ & $28.96 \pm 3.32$ & 96. & \pm 3.52 & $30.01 \pm 3.19$ & $59.62 \pm 2.72$ & $62.56 \pm 2.79$ \\
\hline $18-21$ & 88 & $56.59 \pm 1.72$ & $33.68 \pm 4.18$ & & $6 \pm 4.41$ & $34.25 \pm 3.57$ & $62.17 \pm 3.15$ & $64.93 \pm 3.28$ \\
\hline Total & 500 & $54.46 \pm 2.19$ & $28.30 \pm 4.16$ & 92. & $9 \pm 6.30$ & $30.94 \pm 2.23$ & $57.64 \pm 4.49$ & $60.47 \pm 4.48$ \\
\hline \multicolumn{9}{|c|}{ FEMALES } \\
\hline $3-7$ & 155 & $51.84 \pm 2.07$ & $24.60 \pm 1.87$ & 84. & $5 \pm 5.28$ & $29.31 \pm 1.88$ & $50.52 \pm 3.28$ & $53.38 \pm 3.37$ \\
\hline $8-12$ & 87 & $53.70 \pm 1.76$ & $27.71 \pm 2.43$ & 91. & $4 \pm 5.20$ & $30.34 \pm 2.18$ & $56.01 \pm 2.92$ & $58.90 \pm 2.87$ \\
\hline $13-17$ & 170 & $54.98 \pm 1.58$ & $29.16 \pm 3.00$ & 95. & $4 \pm 4.57$ & $30.70 \pm 2.54$ & $58.78 \pm 3.03$ & $61.68 \pm 3.12$ \\
\hline $18-21$ & 88 & $56.57 \pm 1.72$ & $31.14 \pm 3.30$ & & $0 \pm 3.62$ & $32.02 \pm 3.24$ & $62.14 \pm 2.91$ & $65.10 \pm 2.73$ \\
\hline Total & 500 & $54.27 \pm 2.00$ & $28.15 \pm 2.75$ & & $6 \pm 5.81$ & $30.59 \pm 1.12$ & $56.86 \pm 4.92$ & $59.77 \pm 4.95$ \\
\hline
\end{tabular}

$\mathrm{OCD}=$ Outer Intercanthal Distance, $\mathrm{ICD}=$ Inner Intercanthal Distance, $\mathrm{HC}=$ Head Circumference, $\mathrm{Cl}=\mathrm{Canthal}$ Index, $\mathrm{NIPD}=$ Near Interpupillary Distance, FIPD= Far Interpupillary Distance. SD= Standard Deviation.

Table 2. Mean and standard deviation of some craniofacial dimensions of ljaw males by age.

\begin{tabular}{|c|c|c|c|c|c|c|c|}
\hline Age & $\mathrm{N}$ & $\mathrm{OCD}(\mathrm{mm})$ & $\operatorname{ICD}(\mathrm{mm})$ & $\operatorname{NIPD}(\mathrm{mm})$ & $\operatorname{FIPD}(\mathrm{mm})$ & $\mathrm{Cl}$ & $\mathrm{HC}(\mathrm{cm})$ \\
\hline & & mean \pm SD & mean \pm SD & mean $\pm S D$ & mean $\pm S D$ & mean $\pm S D$ & mean \pm SD \\
\hline 3 & 54 & $79.77 \pm 3.35$ & $23.74 \pm 1.54$ & $50.01 \pm 2.83$ & $52.96 \pm 3.01$ & $29.66 \pm 1.77$ & $50.34 \pm 1.87$ \\
\hline 4 & 35 & $84.14 \pm 2.93$ & $25.37 \pm 1.51$ & $51.11 \pm 2.36$ & $54.20 \pm 2.31$ & $30.14 \pm 1.72$ & $51.40 \pm 1.16$ \\
\hline 5 & 24 & $84.66 \pm 3.63$ & $25.92 \pm 1.34$ & $51.50 \pm 2.78$ & $54.37 \pm 2.79$ & $30.59 \pm 1.60$ & $51.79 \pm 1.87$ \\
\hline 6 & 22 & $86.90 \pm 4.18$ & $25.95 \pm 1.78$ & $53.72 \pm 2.81$ & $56.72 \pm 3.02$ & $29.38 \pm 1.92$ & $52.48 \pm 1.89$ \\
\hline 7 & 17 & $89.50 \pm 2.98$ & $26.50 \pm 2.25$ & $55.06 \pm 2.51$ & $57.93 \pm 2.79$ & $29.83 \pm 2.93$ & $53.35 \pm 1.27$ \\
\hline 8 & 12 & $93.77 \pm 5.76$ & $27.00 \pm 1.22$ & $57.11 \pm 3.82$ & $59.66 \pm 3.84$ & $28.70 \pm 0.87$ & $54.18 \pm 2.59$ \\
\hline 9 & 20 & $92.30 \pm 4.69$ & $27.07 \pm 1.93$ & $56.46 \pm 3.75$ & $59.07 \pm 3.63$ & $29.32 \pm 1.93$ & $54.56 \pm 1.41$ \\
\hline 10 & 18 & $90.94 \pm 3.31$ & $26.72 \pm 1.87$ & $57.16 \pm 2.28$ & $59.66 \pm 2.24$ & $29.42 \pm 2.40$ & $53.82 \pm 1.56$ \\
\hline 11 & 12 & $93.58 \pm 2.67$ & $27.66 \pm 2.18$ & $57.75 \pm 3.76$ & $60.25 \pm 3.93$ & $29.59 \pm 2.69$ & $54.39 \pm 2.11$ \\
\hline 12 & 25 & $92.76 \pm 4.79$ & $27.40 \pm 1.95$ & $58.08 \pm 2.61$ & $61.12 \pm 2.77$ & $29.68 \pm 2.07$ & $54.68 \pm 1.58$ \\
\hline 13 & 30 & $95.03 \pm 3.43$ & $26.80 \pm 1.58$ & $58.66 \pm 2.03$ & $61.53 \pm 1.83$ & $28.24 \pm 2.01$ & $54.90 \pm 1.45$ \\
\hline 14 & 39 & $95.43 \pm 3.13$ & $27.32 \pm 2.33$ & $59.06 \pm 2.01$ & $61.87 \pm 2.22$ & $28.35 \pm 2.09$ & $54.86 \pm 1.43$ \\
\hline 15 & 28 & $95.60 \pm 4.45$ & $28.92 \pm 2.80$ & $59.67 \pm 2.37$ & $62.71 \pm 2.24$ & $30.27 \pm 2.67$ & $55.28 \pm 1.61$ \\
\hline 16 & 35 & $97.31 \pm 3.16$ & $30.08 \pm 3.38$ & $60.17 \pm 2.82$ & $63.08 \pm 2.74$ & $30.92 \pm 3.45$ & $55.99 \pm 1.43$ \\
\hline 17 & 35 & $97.75 \pm 2.86$ & $31.45 \pm 4.29$ & $61.10 \pm 3.40$ & $64.10 \pm 3.49$ & $32.11 \pm 3.91$ & $55.96 \pm 1.38$ \\
\hline 18 & 16 & $96.60 \pm 4.96$ & $33.30 \pm 3.74$ & $61.10 \pm 3.17$ & $64.20 \pm 3.85$ & $34.42 \pm 2.92$ & $56.14 \pm 1.42$ \\
\hline 19 & 19 & $97.84 \pm 4.51$ & $33.89 \pm 4.54$ & $61.78 \pm 3.08$ & $64.15 \pm 3.30$ & $34.58 \pm 3.76$ & $56.99 \pm 1.67$ \\
\hline 20 & 23 & $97.26 \pm 3.99$ & $33.04 \pm 3.63$ & $62.04 \pm 3.62$ & $64.82 \pm 3.40$ & $33.67 \pm 3.21$ & $56.04 \pm 1.95$ \\
\hline 21 & 30 & $99.33 \pm 4.29$ & $34.63 \pm 4.53$ & $63.30 \pm 2.57$ & $66.33 \pm 2.61$ & $34.72 \pm 3.69$ & $57.01 \pm 1.45$ \\
\hline
\end{tabular}

Total number of subjects $=500$ subjects. $\mathrm{N}=$ number of subjects, $\mathrm{OCD}=$ Outer canthal distance, ICD $=$ Inner canthal distance, NIPD $=$ Near Interpupillary distance, FIPD= Far Interpupillary distance, $\mathrm{Cl}=$ Canthal Index, $\mathrm{HC}=$ Head Circumference. 
Table 3. Mean and standard deviation of some craniofacial dimensions of ljaw females by age.

\begin{tabular}{|c|c|c|c|c|c|c|c|}
\hline Age & $\mathrm{N}$ & $\mathrm{OCD}(\mathrm{mm})$ & $\mathrm{ICD}(\mathrm{mm})$ & NIPD(mm) & $\mathrm{FIPD}(\mathrm{mm})$ & $\mathrm{Cl}$ & $\mathrm{HC}(\mathrm{cm})$ \\
\hline & & mean $\pm \mathrm{SD}$ & mean \pm SD & mean $\pm S D$ & mean \pm SD & mean \pm SD & mean \pm SD \\
\hline 3 & 51 & $79.87 \pm 3.19$ & $22.94 \pm 1.05$ & $48.41 \pm 2.08$ & $51.13 \pm 2.11$ & $28.74 \pm 1.35$ & $50.83 \pm 1.92$ \\
\hline 4 & 37 & $83.68 \pm 4.26$ & $24.48 \pm 1.24$ & $49.82 \pm 2.83$ & $52.54 \pm 2.80$ & $29.83 \pm 5.49$ & $51.85 \pm 1.83$ \\
\hline 5 & 25 & $86.45 \pm 4.12$ & $25.70 \pm 1.78$ & $51.50 \pm 2.50$ & $54.00 \pm 2.67$ & $28.94 \pm 2.17$ & $52.39 \pm 1.98$ \\
\hline 6 & 22 & $86.18 \pm 5.00$ & $25.95 \pm 1.61$ & $52.18 \pm 2.63$ & $55.31 \pm 2.80$ & $30.23 \pm 2.14$ & $52.80 \pm 1.70$ \\
\hline 7 & 16 & $89.87 \pm 3.99$ & $26.62 \pm 1.14$ & $54.56 \pm 3.93$ & $57.37 \pm 3.82$ & $30.28 \pm 3.45$ & $53.83 \pm 1.94$ \\
\hline 8 & 9 & $90.77 \pm 6.62$ & $27.66 \pm 2.95$ & $56.66 \pm 3.00$ & $59.44 \pm 3.16$ & $30.66 \pm 3.62$ & $53.34 \pm 1.01$ \\
\hline 9 & 13 & $87.92 \pm 4.82$ & $26.61 \pm 1.85$ & $55.76 \pm 3.76$ & $58.69 \pm 3.56$ & $30.27 \pm 1.51$ & $51.76 \pm 2.18$ \\
\hline 10 & 18 & $90.50 \pm 5.12$ & $26.72 \pm 2.32$ & $55.27 \pm 3.42$ & $58.05 \pm 3.33$ & $29.53 \pm 2.61$ & $53.90 \pm 1.07$ \\
\hline 11 & 17 & $91.00 \pm 5.54$ & $29.25 \pm 4.43$ & $56.16 \pm 2.44$ & $59.25 \pm 2.45$ & $30.21 \pm 1.74$ & $53.81 \pm 1.65$ \\
\hline 12 & 27 & $93.24 \pm 4.35$ & $28.72 \pm 2.40$ & $56.43 \pm 2.50$ & $59.36 \pm 2.59$ & $30.47 \pm 2.71$ & $53.96 \pm 1.64$ \\
\hline 13 & 44 & $93.95 \pm 5.23$ & $28.68 \pm 3.31$ & $58.10 \pm 3.42$ & $60.16 \pm 4.00$ & $30.33 \pm 2.90$ & $54.27 \pm 1.57$ \\
\hline 14 & 32 & $94.15 \pm 5.29$ & $29.25 \pm 3.47$ & $58.25 \pm 3.16$ & $61.12 \pm 3.07$ & $31.02 \pm 2.75$ & $54.80 \pm 1.71$ \\
\hline 15 & 30 & $95.57 \pm 3.32$ & $28.71 \pm 2.20$ & $58.39 \pm 2.16$ & $61.25 \pm 2.13$ & $30.05 \pm 2.21$ & $55.16 \pm 1.26$ \\
\hline 16 & 40 & $96.68 \pm 3.55$ & $29.71 \pm 2.97$ & $59.88 \pm 2.69$ & $62.28 \pm 3.06$ & $30.50 \pm 2.21$ & $55.04 \pm 1.40$ \\
\hline 17 & 20 & $95.75 \pm 4.65$ & $29.80 \pm 2.37$ & $59.85 \pm 2.64$ & $62.65 \pm 2.94$ & $31.16 \pm 2.23$ & $55.51 \pm 2.91$ \\
\hline 18 & 10 & $97.00 \pm 2.66$ & $30.20 \pm 3.58$ & $60.40 \pm 3.62$ & $63.50 \pm 3.68$ & $31.16 \pm 3.85$ & $56.12 \pm 1.84$ \\
\hline 19 & 19 & $96.15 \pm 3.53$ & $29.78 \pm 3.29$ & $60.89 \pm 3.05$ & $63.84 \pm 2.91$ & $30.98 \pm 3.21$ & $55.55 \pm 2.91$ \\
\hline 20 & 24 & $98.04 \pm 3.59$ & $31.04 \pm 3.14$ & $62.56 \pm 2.29$ & $65.39 \pm 2.21$ & $31.65 \pm 3.05$ & $56.62 \pm 1.89$ \\
\hline 21 & 34 & $97.16 \pm 4.11$ & $32.30 \pm 3.08$ & $62.76 \pm 2.55$ & $65.86 \pm 2.43$ & $33.22 \pm 3.00$ & $57.07 \pm 1.59$ \\
\hline
\end{tabular}

Total number of subjects $=500$ subjects. $\mathrm{N}=$ number of subjects, OCD= Outer canthal distance, ICD= Inner canthal distance, $\mathrm{NIPD}=$ Near Interpupillary distance, FIPD= Far Interpupillary distance, $\mathrm{Cl}=\mathrm{Canthal}$ Index, $\mathrm{HC}=\mathrm{Head}$ Circumference.

\section{DISCUSSION}

Craniofacial anthropometry has become an important tool to both clinical geneticists and reconstructive surgeons. Ocular adnexal changes and somatometric traits of the face such as epicanthus, telecanthus and widely spaced eyebrows may create an illusory error in the identification of certain craniofacial syndromes, and reliable methods are needed for the diagnosis of some craniofacial anomalies (DeMyer, 1967; Pryor, 1969; Farkas et al., 1992a \&b).

This study found the overall inner intercanthal distance for males to be slightly larger than those of females and for the whole group. The differences were significant $(p<0.001)$. The overall mean inner intercanthal distance for males and females subjects are $28.30 \pm 4.16 \mathrm{~mm}$ and $28.15 \pm 2.75 \mathrm{~mm}$ respectively while the overall mean outer intercanthal distance for male and female subjects are $92.49 \pm 6.30 \mathrm{~mm}$ and $91.96 \pm 5.81 \mathrm{~mm}$ respectively. The mean inner and outer intercanthal distance for males at age group 812 years was $27.16 \pm 1.91 \mathrm{~mm}$ and $92.20 \pm 4.40 \mathrm{~mm}$ respectively. The value obtained for the inner intercanthal distance was lower than that obtained by Juberg et al., (1975) for African American males and Evereklioglu et al.,(2002), for Turkish male children aged between 7-15 years. The values obtained for the ljaw male children of 8-12 years were higher than that obtained by Evereklioglu et al., (2002) for Turkish children of 7-15 years. The values obtained for the females in this study of age group 8-12 years for inner and outer intercanthal distances are $27.71 \pm 2.43 \mathrm{~mm}$ and $91.34 \pm 5.20 \mathrm{~mm}$ respectively. The value for the inner intercanthal distance was lower than that obtained by Juberg et al., (1975) for African American females, Quant and Woo, (1992) for Chinese females, Freihofer (1980) and Murphy; Laskin (1990); $31.2 \pm 2.5 \mathrm{~mm}$ and $33.9 \pm \mathrm{mm}$ respectively. It is similar to the Turkish female children at 7 years (Evereklioglu et al., (2002), while 
for the outer intercanthal distance, the values obtained from this study was higher than that obtained by Evereklioglu et al., (2002), Juberg et al., (1975).

The study also found the head circumference for males to be larger than those of females and the differences were significant $(p<0.001)$. The value obtained from this study were lower than those obtained by Osuobeni and Al-musa, (1993) which was $57.43 \pm 1.46 \mathrm{~cm}$ for male children between $11.87 \pm 2.87$ years and in female children between $11.72 \pm 2.75$ years. The overall mean values obtained for males are similar to that obtained for the Turkish population by Evereklioglu et al., (2002) but the values for the females in this are larger than that obtained for females in the Turkish population. The overall near interpupillary distance for males in this was larger than that of females and for the groups as a whole. The differences were significant $(p<0.001)$. The far interpupillary distance for males were also larger than that of females except for age group 1821 years where the value for females were slightly higher. The near interpupillary distance of males in this study at age $8-12$ years $(57.13 \pm 3.23 \mathrm{~mm}$ and $56.01 \pm 2.92 \mathrm{~mm}$ for males and females respectively) was larger than that of Arabian children of 5-15 years old $(55.68 \pm 2.52 \mathrm{~mm})$ Osuobeni and Al-Musa, 1993). The values obtained for the far interpupillary distance in this study was similar to that obtained by Lucas and Pryor, (1935) $59 \pm 4.4 \mathrm{~mm}$ and $59.5 .2 \mathrm{~mm}$ for males and females respectively. The values obtained in this study for canthal indices were lower than that obtained by Oladipo et al., (2008) for ljaw males (37.04) and females (33.11). While for the total population, the mean canthal index for the ljaws in the study by Oladipo et al., (2008) was 33.87. For this study the total mean of the canthal index was $30.94 \pm 2.23$ for males and $30.59 \pm 1.12$ for females which was lower than that obtained by Oladipo et al., (2008). But were higher than that obtained by Oladipo et al., (2009), 24.38 and 29.38 respectively for Urhobo males and females, while that obtained for Itsekiri males and females were 26.03 and 27.07 respectively.

\section{CONCLUSION}

Knowledge gained from this study will help in the understanding of the orbito-cranial growth patterns of males and females of ljaw ethnic origin, early diagnosis of craniofacial syndrome and surgical management of craniofacial deformities. Craniofacial dimensions should be perfomed with normal standards specific for age, sex, race and ethnic group. The data obtained in this study is important to maxillofacial surgeons, dysmorphologists, clinicians and forensic scientist.

\section{REFERENCE}

Cem Evereklioglu, Cengiz Yakinci, Hamdi Er, Selim Doganay, Yasar Durmaz (2001). Normative values of craniofacial measurements in idiopathic benign macrocephalic children. The cleft Palate Craniofac J. pp 260-263.

Cem Evereklioglu, Doganay S, Er H, Gunduz A, Tercan M, Balat A, Cumurcu T (2002). Craniofacial anthropometry in a Turkish population. Cleft palate Craniofac J. Mar; 39(2): 208-18.

Donald RA, Douglas RB, John B (199). Stedman's Medical Dictionary, $27^{\text {th }}$ editn Lippincott Williams Publishers. Pg 95.

Farkas LG, Posnick JC, Hreezko TM. (1992a): Anthropometric growth study of the head. Cleft Palate Craniofac J. 29:303-308.

Farkas LG, Posnick JC, Hreezko TM, Pron GE (1992b): Growth patterns in orbital region. Cleft Palate Craniofac J. 29: 315-318.

Kaimbo DK, Kayembe D (1994). Orbital measurements in Zairian children. Inner canthal, outer orbital, interpupillary distances and protosis. J Fr Ophtalmol. 17(89): 496-500.

Laestedius ND, Aase JM, Smith DW (1979). Normal inner canthal and outer orbital dimensions. J Pediatr. 74:465-468.

Lakshminarayana P, Janardhan K, David HS (1991). Anthropometry for syndromology. Indian $\mathrm{J}$ Pediatr. 58:253-258.

Oladipo Gabriel S, Fawehinmi Hakeem B, Okoh Peter D. (2009). Canthal indices of Urhobo and Itsekiri ethnic groups. Australian Journal of Basic and Applied Sciences, 3(4): 3093-3096.

Osuobeni FP, Al-Fahdi M (1994). Differences between anatomical and physiological inter-pupillary distance. J Am Optom Assoc. 65:265-271.

Osuobeni EP, Al-Musa KA (1993). Gender difference in interpupillary distance among Arabs. Optm Vis Sci. 70:1027-1030.

Pinzer T, Gollogly J, Krishnan KG, Schackert G, Laucer G (2008). Telecanthus and hypertelorism in frontoethmoidal meningoencephaoceles and surgical correction of these conditions. Part 1. An orbital anthropomorphometric evaluation of the khmer subpopulation of Cambodia. 19:137-147. 